Aim of the study: The aim of this retrospective chart review was to determine the long-term outcomes and identify prognostic factors that impact the survival of patients with cervical cancer.

Material and methods: A retrospective chart review of 739 patients with International Federation of Gynaecology and Obstetrics (FIGO) stage I-IV cervical cancer treated with surgery, radiation or chemoradiation was performed. Patient charts were evaluated in terms of demographics, clinical outcomes, and survival. Disease-free survival (DFS) and overall survival (OS) were calculated with the Kaplan-Meier method, and differences in surviva were compared with the log-rank test. Multivariate analysis was performed with a Cox proportional hazards model to determine the estimated hazard ratios (HR) with $95 \%$ confidence intervals (Cl) for each prognostic factor. Results: The Cox proportional hazards model demonstrated that pelvic nodal metastasis $(p=0.018)$, parametrial invasion $(p=0.015)$, and presence of disease in the surgical margin ( $p=$ $=0.011$ ) were all independent prognostic factors for OS. The 5-year OS rate of patients with negative pelvic lymph nodes was $67.1 \%$, which was higher than the rate for those with positive nodes at $49.0 \%(p<0.05)$. The 5 -year OS rate was $54.3 \%$ for patients with metastasis to the parametrium, $79.2 \%$ with a cancer-free parametrium, $60.9 \%$ with a cancer-positive surgical margin, $85.4 \%$ with a cancer-negative surgical margin, and $64.3 \%$ with a $1-3 \mathrm{~mm}$ close surgical margin $(p<0.05)$.

Conclusions: Assessing pelvic lymph nodes, the parametrium, and surgical margins is important for survival and may aid in better identifying patients who would derive greater benefits from receiving adjuvant therapies and more aggressive treatments.

Key words: cervical cancer, parametrial invasion, pelvic lymph node, prognostic factors, survival.

Contemp Oncol (Pozn) 2015; 19 (2): 130-136 DOI: $10.5114 /$ wo.2015.51418

\section{Evaluation of outcome and prognostic factors in 739 patients with uterine cervix carcinoma: a single institution experience}

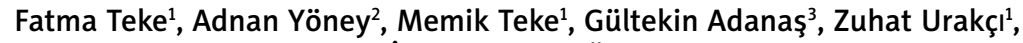
Gül Türkcü ${ }^{1}$, Bekir Eren ${ }^{4}$, Ali İnal ${ }^{1}$, Mustafa Ünsal ${ }^{4}$

${ }^{1}$ Dicle University, Diyarbakır, Turkey

${ }^{2}$ Karadeniz Technical University, Trabzon, Turkey

${ }^{3}$ Zeynep Kamil Training and Research Hospital, Istanbul, Turkey

${ }^{4}$ Okmeydanı Training and Research Hospital, Istanbul, Turkey

\section{Introduction}

Cervical cancer is a major public health concern as it is the second leading cause of cancer mortality following breast cancer in women. As one of the most commonly diagnosed malignancies, there are nearly 500,000 new cases of cervical cancer diagnosed each year. Most cervical carcinomas are diagnosed in their early stages with PAP smear screening in developing countries [1]. Squamous cell carcinoma (SCC) constitutes more than 75\% of all diagnosed cervical cancers, but the incidence of SCC has been decreasing while the incidence of adenocarcinoma has been rising [2].

Various histological and clinical factors such as tumour size [3], parametrial invasion (PI) [4-6], cervical stromal invasion depth [4, 7, 8], lymphovascular space invasion (LVSI) [9-11], FIGO stage [7, 12], tissue histology [4, 6, 8], tumour grade [4, 13, 14], and lymph node metastasis [15-19] are associated with survival and prognosis in cervical cancer patients.

The aim of this retrospective study was to assess long-term outcomes and identify independent prognostic factors for patients with cervical carcinoma.

\section{Material and methods}

Patients

A retrospective chart analysis of 739 patients diagnosed with cervical carcinoma admitted between January 1996 and December 2006 to the Radiation Oncology Clinic at the GH Okmeydanı Training and Research Hospital was performed. Patient demographics, clinical progression, and survival were assessed. All patients at stages I-IV were examined in terms of utilized treatment modalities and prognosis. Patients with adenocarcinoma, squamous cell carcinoma, adenosquamous carcinoma, anaplastic carcinoma, small cell carcinoma, and clear cell carcinoma were included in this study. Surgery reports, pathology reports, and clinical follow-up notes in patients' clinical archives were reviewed. Patient age, surgery type and date, histopathological diagnosis, tumour grade, stage, and size, parametrial extension, lymphovascular space invasion (LVSI), pelvic lymph node metastasis, surgical margin status (SMS), depth of stromal invasion (DSI), treatment modality, recurrence date, date of metastasis, and date of death or last follow-up appointment were verified for each subject. 


\section{Staging}

Patients were staged according to the International Federation of Gynaecology and Obstetrics (FIGO) staging criteria. Pre-treatment evaluation comprised a pelvic examination by a radiation oncologist and a gynaecological oncologist. Imaging to detect the presence of a primary tumour and metastases included computed tomography and/or magnetic resonance imaging of the chest, abdomen and pelvis. When symptoms of tumour invasion were suspected, proctoscopy, cystoscopy or intravenous pyelogram was performed. Positive lymph nodes were identified by radiographic evaluation. Lymph nodes were reported as pathologically enlarged according to the physician's radiology report if the lymph node was greater than $1 \mathrm{~cm}$ on imaging.

\section{Follow-up}

After receiving cervical cancer treatments, all patients were initially scheduled for follow-up appointments every 3 months, then every 6 months over the next 3 years, and then annually until disease recurrence or death. Patients received follow-up over an average of 59.0 months with a range of 4 months up to 166 months.

\section{Surgery}

Out of all the patients, 307 underwent operations. Almost all of the subjects were treated with a type I, II or III hysterectomy with or without a pelvic and para-aortic lymphadenectomy. One hundred and sixty-five patients underwent type I hysterectomy, referred to as extrafascial, or simple, hysterectomy, that removes the cervix along with the uterine corpus but does not require mobilization of the ureter or removal of a significant amount of the parametria. Sixty-three patients underwent type II hysterectomy, commonly known as (modified) radical hysterectomy, or the Wertheim operation. It requires more extensive dissection than the simple hysterectomy. Sixty-two patients underwent type III hysterectomy, which aims to remove as much parametrial tissue as possible. Only 1 patient was treated with type IV, that is, extended radical hysterectomy. Four hundred and eighteen patients did not undergo surgery, and 14 of those patients declined surgery.

\section{Radiotherapy}

Intracavitary brachytherapy was delivered to 573 patients at a high dose rate (HDR) or at a low dose rate (LDR). LDR brachytherapy was performed in 48 cases with caesium-137, in a total dose of 80 to 100 Gy at point A. HDR brachytherapy was applied to the involved parametria by using a source made of iridium-192 in 1-7 fractions in 525 patients, and the average intracavitary radiotherapy (ICRT) dose for these patients was $24 \mathrm{~Gy}$, ranging from 8 to $35 \mathrm{~Gy}$. Brachytherapy was applied alone in only 1 patient with stage IA disease. Three cases were given HDR brachytherapy following external beam radiotherapy (EBRT) preoperatively. Four hundred and sixty-nine patients underwent postoperative EBRT and then brachytherapy.
External pelvic radiotherapy was directed throughout the entire pelvic radiation field at 1.8 or 2.0 Gy/fraction/ day for a total of five treatments in a week. The average total radiation dose involving pelvic radiation and parametrium boost doses was $50 \mathrm{~Gy}$, ranging from 30 to $70 \mathrm{~Gy}$. Parametrium boost was applied in the 73 patients with disease extension to the parametrium or the pelvic side wall(s). The median parametrium boost dose was 1000 cGy (range: 400-2000 cGy). These patients with locally advanced disease who underwent definitive radiation therapy with or without chemotherapy received RT up to a total dose of 70 Gy.

A total of 247 patients received definitive radiation therapy (RT), 181 patients received RT with concurrent chemoradiotherapy (CCRT), and 37 patients were treated with postoperative CCRT. Concurrent chemoradiotherapy was given to patients who had locally advanced disease or high risk factors such as positive surgical margin, involved lymph node, deep stromal invasion, or lymphovascular surface invasion. Preoperative radiation therapy was delivered to 3 patients.

Cisplatin was the chemotherapeutic agent used in all patients treated with CCRT, and it was delivered weekly at a dose of $40 \mathrm{mg} / \mathrm{m}^{2}$, but 4 patients were given epirubicin or gemcitabine instead. A total of 11 patients had suspicious pelvic and para-aortic lymph nodes and were treated with extended-field radiation therapy (EFRT), i.e. external irradiation of pelvic and para-aortic lymph nodes. Para-aortic irradiation was delivered using anteroposterior/posteroanterior and opposed lateral (four-field) arrangements.

\section{Prognostic factors analysed}

Nine putative prognostic factors were chosen based on previously published clinical trials. These prognostic factors were the following: age groups including 25-34, 35-44, 45-54, 55-64, and age $\geq 65$; FIGO stage including IA, IB1, IB2, IIA, IIB, IIIA, IIIB, and IV; negative or positive pelvic lymph node ( $P L N$ ) involvement; negative or positive para-aortic nodal metastasis; negative or positive PI; negative, positive or close margin SMS; $\geq 5 \mathrm{~mm}$ or $<5 \mathrm{~mm} \mathrm{DSI}$; negative or positive LVSI; and greatest tumour diameter at either $<4 \mathrm{~cm}, 4-6 \mathrm{~cm}$, or $>6 \mathrm{~cm}$.

\section{Statistical methods}

Overall survival (OS) was measured in months from the first day of treatment until the last follow-up appointment or death. Disease-free survival (DFS) was measured in months beginning at the first day of treatment until pelvic or metastatic cancer recurrence was identified. Data were analysed by SPSS statistical software version 12.0.1 (SPSS Inc., Chicago, IL). Kaplan-Meier curves were used to calculate both OS and DFS, while the log-rank test was used to compare differences in survival. Multivariate analysis was performed with the Cox regression model to estimate hazard ratio (HR) with a 95\% confidence interval (Cl) for each prognostic factor. A $p$-value $<0.05$ was considered statistically significant. 
Table 1. Patient demographics and clinical characteristics

\begin{tabular}{|c|c|c|c|}
\hline Variables & & $\begin{array}{c}\text { Number } \\
(n)\end{array}$ & $\begin{array}{c}\text { Percentage } \\
(\%)\end{array}$ \\
\hline Age (years) & $\begin{array}{l}\text { average } \\
\text { range }\end{array}$ & $\begin{array}{c}52 \\
25-80\end{array}$ & \\
\hline $\begin{array}{l}\text { Age groups } \\
\text { (years) }\end{array}$ & $\begin{array}{c}25-34 \\
35-44 \\
45-54 \\
55-64 \\
\geq 65\end{array}$ & $\begin{array}{c}25 \\
139 \\
266 \\
198 \\
111\end{array}$ & $\begin{array}{c}3.4 \\
18.8 \\
36.0 \\
26.8 \\
15.0\end{array}$ \\
\hline FIGO stage & $\begin{array}{l}\text { IA1 } \\
\text { IA2 } \\
\text { IB1 } \\
\text { IB2 } \\
\text { IIA } \\
\text { IIB } \\
\text { IIIA } \\
\text { IIIB } \\
\text { IVA } \\
\text { IVB }\end{array}$ & $\begin{array}{c}5 \\
11 \\
104 \\
91 \\
55 \\
357 \\
31 \\
33 \\
43 \\
9\end{array}$ & $\begin{array}{c}0.7 \\
1.5 \\
14.1 \\
12.3 \\
7.4 \\
48.3 \\
4.2 \\
4.5 \\
5.8 \\
1.2\end{array}$ \\
\hline $\begin{array}{l}\text { Tumour } \\
\text { histology }\end{array}$ & $\begin{array}{c}\text { squamous cell } \\
\text { carcinoma } \\
\text { adenocarcinoma } \\
\text { adenosquamous } \\
\text { carcinoma } \\
\text { other }\end{array}$ & $\begin{array}{l}68 \\
11\end{array}$ & $\begin{array}{l}9.2 \\
1.5 \\
1.5\end{array}$ \\
\hline PLN & $\begin{array}{l}\text { negative } \\
\text { positive } \\
\text { unknown }\end{array}$ & $\begin{array}{c}577 \\
120 \\
42\end{array}$ & $\begin{array}{c}78.1 \\
16.2 \\
5.7\end{array}$ \\
\hline $\begin{array}{l}\text { Para-aortic } \\
\text { nodal } \\
\text { metastasis }\end{array}$ & $\begin{array}{l}\text { negative } \\
\text { positive } \\
\text { unknown }\end{array}$ & $\begin{array}{c}673 \\
19 \\
47\end{array}$ & $\begin{array}{l}91.1 \\
2.5 \\
6.4\end{array}$ \\
\hline $\mathrm{PI}$ & $\begin{array}{l}\text { negative } \\
\text { positive } \\
\text { unknown }\end{array}$ & $\begin{array}{c}273 \\
463 \\
3\end{array}$ & $\begin{array}{c}36.9 \\
62.7 \\
0.4\end{array}$ \\
\hline $\begin{array}{l}\text { Surgical } \\
\text { margin }\end{array}$ & $\begin{array}{c}\text { negative } \\
\text { positive } \\
\text { close margin }(1-3 \mathrm{~mm}) \\
\text { unknown }\end{array}$ & $\begin{array}{c}126 \\
33 \\
7 \\
143\end{array}$ & $\begin{array}{c}17.1 \\
4.5 \\
0.9 \\
19.4\end{array}$ \\
\hline $\begin{array}{l}\text { Stromal } \\
\text { invasion } \\
\text { depth }\end{array}$ & $\begin{array}{l}\geq 5 \mathrm{~mm} \\
<5 \mathrm{~mm} \\
\text { unknown }\end{array}$ & $\begin{array}{c}20 \\
200 \\
519\end{array}$ & $\begin{array}{c}2.7 \\
27.1 \\
70.2\end{array}$ \\
\hline LVSI & $\begin{array}{l}\text { negative } \\
\text { positive } \\
\text { unknown }\end{array}$ & $\begin{array}{c}17 \\
56 \\
666\end{array}$ & $\begin{array}{c}2.3 \\
7.6 \\
90.1\end{array}$ \\
\hline $\begin{array}{l}\text { Greatest } \\
\text { tumour } \\
\text { diameter }\end{array}$ & $\begin{array}{l}<4 \mathrm{~cm} \\
4-6 \mathrm{~cm} \\
>6 \mathrm{~cm} \\
\text { unknown }\end{array}$ & $\begin{array}{c}203 \\
243 \\
71 \\
222\end{array}$ & $\begin{array}{c}27.5 \\
32.9 \\
9.6 \\
30\end{array}$ \\
\hline $\begin{array}{l}\text { Tumour } \\
\text { grade }\end{array}$ & $\begin{array}{c}\text { differentiated* } \\
\text { undifferentiated } \\
\text { unknown }\end{array}$ & $\begin{array}{c}422 \\
10 \\
307\end{array}$ & $\begin{array}{c}57.1 \\
1.4 \\
41.5\end{array}$ \\
\hline
\end{tabular}

PLN-pelvic lymph node; PI - parametrial invasion; LVSI - lymphovascular space invasion

\section{Results}

\section{Patient demographics and tumour characteristics}

Patient and tumour characteristics for all 739 patients are displayed in Table 1 . The average patient age was 52 years and ages ranged from 25 to 80 . The mean duration of follow-up was 59 months, ranging from 4 to 166 months. The majority of patients were in the $45-54$ age group, with a rate of $36 \%$. According to tumour histology, 649 (87.8\%) patients had squamous cell carcinoma, while $9.2 \%$ had adenocarcinoma. Out of all subjects, $48.3 \%$ were diagnosed with FIGO stage IIB cervical cancer, and 57.1\% of the patients had differentiated carcinomas at grades I-II. For $32.9 \%$ of patients, the greatest tumour diameter was 4 to $6 \mathrm{~cm}$. Pelvic lymph node involvement was present in $16.2 \%$ of patients, and 89 of these patients were diagnosed with FIGO stage IA-IIB disease. Para-aortic nodal metastasis was absent in $91.1 \%$ of all patients. The surgical margin was positive in $4.5 \%$ of patients who received surgery. Parametrial invasion was present in $62.7 \%$ of patients. Lymphovascular space invasion and DSI could not be determined from the majority of the patient charts.

\section{Treatment}

Therapeutic modalities used to treat all 739 patients are shown in Table 2. Out of all the subjects, $41.5 \%$ underwent surgery and 222 of those patients were diagnosed with FIGO stage IA-IIB cancer. It was observed that 710 of the patients received RT with or without concurrent $\mathrm{CT}$, and only 1 patient received ICRT alone. A total of 28 patients did not receive RT due to advanced age or early stage disease. These patients continued to be followed over time but did not receive further treatments. The majority of patients (622) received external pelvic RT for at least 45 days. The percentage of patients who completed 5000 cGy and higher external beam radiotherapy within 8 weeks was $85.3 \%$ ( 630 patients). The median duration of EBRT was 38 days (min. 15, max. 104 days).

\section{Survival outcomes}

Table 3 demonstrates 5-year and 10-year OS and DFS rates. The mean 5 -year DFS rate was $62.2 \%$ and the mean 10 -year DFS rate was $50.5 \%$ for all 739 patients. The average 5 -year OS rate for all patients was $63.7 \%$ and the average 10 -year OS rate was $50.1 \%$.

\section{Prognostic factor analysis}

The results of the univariate analysis are shown in Table 4. Among the potential prognostic factors determined with univariate analysis, 8 factors were identified as having prognostic significance for OS: age group, FIGO stage, PLN involvement, para-aortic node metastasis, PI, SMS, DSI, and greatest tumour diameter.

Multivariate analysis was performed with the aforementioned 8 prognostic factors that were found to be statistically significant in univariate analysis. The Cox proportional hazard model showed that pelvic node metastasis $(p=0.018), \mathrm{PI}(p=0.015)$, and SMS $(p=0.011)$ were 
Table 2. Treatment overview

\begin{tabular}{|c|c|c|c|}
\hline \multicolumn{2}{|c|}{ Treatment features } & \multirow{2}{*}{$\begin{array}{c}\text { Number } \\
\text { (n) } \\
307 \\
418 \\
14\end{array}$} & \multirow{2}{*}{$\begin{array}{c}\text { Percentage } \\
\text { (\%) } \\
41.5 \\
56.6 \\
1.9\end{array}$} \\
\hline $\begin{array}{l}\text { Operation } \\
\text { status }\end{array}$ & $\begin{array}{l}\text { operation indicated } \\
\text { no operation indicated } \\
\text { patient rejected } \\
\text { operation }\end{array}$ & & \\
\hline $\begin{array}{l}\text { Treatment } \\
\text { modality }\end{array}$ & $\begin{array}{l}\text { definitive RT } \\
\text { CCRT } \\
\text { preop-RT } \\
\text { postop-RT } \\
\text { postop-CCRT } \\
\text { only ICRT } \\
\text { palliative RT } \\
\text { no treatment }\end{array}$ & $\begin{array}{c}247 \\
181 \\
3 \\
240 \\
37 \\
1 \\
2 \\
28\end{array}$ & $\begin{array}{c}33.4 \\
24.5 \\
0.4 \\
32.5 \\
5.0 \\
0.1 \\
0.3 \\
3.8\end{array}$ \\
\hline $\begin{array}{l}\text { External RT } \\
\text { time }\end{array}$ & $\begin{array}{l}\text { average } \\
\text { range } \\
<45 \text { days } \\
45-60 \text { days } \\
61-80 \text { days } \\
>80 \text { days }\end{array}$ & $\begin{array}{c}38 \text { days } \\
15-104 \text { days } \\
622 \\
67 \\
14 \\
7\end{array}$ & $\begin{array}{c}84.2 \\
9.1 \\
1.9 \\
0.9\end{array}$ \\
\hline $\begin{array}{l}\text { Definitive } \\
\text { RT dose }\end{array}$ & $\begin{array}{l}\text { average } \\
\text { range }\end{array}$ & $\begin{array}{c}50 \text { Gy } \\
45-70 \text { Gy }\end{array}$ & \\
\hline $\begin{array}{l}\text { Postop-RT } \\
\text { dose }\end{array}$ & $\begin{array}{l}\text { average } \\
\text { range }\end{array}$ & $\begin{array}{c}50 \text { Gy } \\
45-62 \text { Gy }\end{array}$ & \\
\hline ICRT & $\begin{array}{l}\text { absent } \\
\text { present }\end{array}$ & $\begin{array}{l}573 \\
166\end{array}$ & $\begin{array}{l}77.5 \\
22.5\end{array}$ \\
\hline ICRT dose & $\begin{array}{l}\text { median } \\
\text { range }\end{array}$ & $\begin{array}{l}24 \mathrm{~Gy} \\
\text { 8-35 Gy }\end{array}$ & \\
\hline $\begin{array}{l}\text { Para-aortic } \\
\text { field RT }\end{array}$ & $\begin{array}{l}\text { absent } \\
\text { present }\end{array}$ & $\begin{array}{c}728 \\
11\end{array}$ & $\begin{array}{c}98.5 \\
1.5\end{array}$ \\
\hline $\begin{array}{l}\text { Parametrial } \\
\text { boost }\end{array}$ & $\begin{array}{l}\text { absent } \\
\text { present }\end{array}$ & $\begin{array}{c}666 \\
73\end{array}$ & $\begin{array}{c}90.2 \\
9.8\end{array}$ \\
\hline $\begin{array}{l}\text { Parametrial } \\
\text { boost dose }\end{array}$ & $\begin{array}{l}\text { median } \\
\text { range }\end{array}$ & $\begin{array}{l}10 \mathrm{~Gy} \\
4-20 \mathrm{~Gy}\end{array}$ & \\
\hline
\end{tabular}

$R T$ - radiation therapy; CCRT - concurrent chemotherapy; ICRT - intracavitary radiotherapy

independent prognostic factors for OS. The results of the multivariate analysis are displayed in Table 5.

Estimated 5-year and 10-year OS rates according to PLN, PI and SMS are shown in Table 6. The 5-year and 10year OS rates were $49 \%$ and $41.1 \%$ for positive PLN, respectively, and $67.1 \%$ and $52.0 \%$ for negative PLN, in that order. The 5 -year OS rate was $54.3 \%$ and the 10 -year OS rate was $39.7 \%$ for positive $\mathrm{PI}$, and $79.2 \%$ and $66.7 \%$ for negative $\mathrm{PI}$, respectively. The 5 -year OS rate was $60.9 \%$ and the 10 -year OS rate was $51.4 \%$ for positive surgical margin, and $85.4 \%$ and $64.5 \%$ for negative surgical margin, in that order. Both 5-year and 10 -year OS rates were $64.3 \%$ for a close surgical margin of 1-3 mm. Overall survival curves for PLN involvement, PI and SMS are shown in Figures 1, 2 and 3.

\section{Discussion}

Various histopathological and clinical factors such as tumour size $[3,4,20], \mathrm{PI}[4,6,16,21]$, depth of cervical stromal invasion $[4,7,8]$, lymphovascular space invasion [9-11], FIGO stage [7, 12], cancer histological type [4, 6, 8], tumour grade [4, 13, 14], SMS [18, 22-24], and lymph node metastasis [15-19, 23] are all associated with survival and
Table 3. Survival outcomes

$\begin{array}{lcc}\text { Survival } & \text { OS (\%) } & \text { DFS (\%) } \\ \text { 5-year survival } & 63.7 & 62.2 \\ \text { 10-year survival } & 50.1 & 50.5\end{array}$

DFS - disease-free survival; OS - overall survival

Table 4. Survival time univariate analysis according to prognostic factor

\begin{tabular}{lccc} 
Prognostic factor & $\begin{array}{c}\text { Log-rank } \\
\text { test value }\end{array}$ & $\begin{array}{c}\text { Degrees of } \\
\text { freedom }\end{array}$ & $p$-value \\
\hline Age group & 18.24 & 4 & 0.001 \\
FIGO stage & 123.7 & 7 & 0.000 \\
PLN involvement & 14.6 & 2 & 0.001 \\
Para-aortic node metastasis & 21.0 & 2 & 0.000 \\
PI & 58.1 & 2 & 0.000 \\
LVSI & 4.02 & 2 & 0.134 \\
SMS & 54.1 & 4 & 0.000 \\
DSI & 21.7 & 2 & 0.000 \\
Greatest tumour diameter & 55.5 & 3 & 0.000
\end{tabular}

PLN - pelvic lymph node; PI - parametrial invasion; LVSI - lymphovascular space invasion; SMS - surgical margin status; DSI - depth of stromal invasion

prognosis for patients with cervical cancer. We demonstrated that PLN involvement, PI, and SMS are all independent prognostic factors for overall survival.

Even though FIGO staging for cervical cancers does not take into account the presence of cancer in pelvic or para-aortic lymph nodes, this staging system provides significant prognostic information. Lymph node cancer status is important when deciding what therapeutic modality is appropriate. As the FIGO stage becomes more advanced, the possibility of parametrial involvement and lymph node metastasis increases as well. The presence of PLN metastases has been found to be associated with decreased overall survival, increased rates of disease recurrence, and the development of distant metastases [15-19, 23].

Liu et al. [16] demonstrated that the 5-year OS rate for patients with PLN metastasis was only $52 \%$, while patients without pelvic lymph node metastasis had a 5-year OS rate of $91 \%$. In their study, the number of involved PLN was also significant. For 1 positive PLN the 5-year OS rate was $80 \%$, and for 2 or more positive nodes the 5 -year OS rate was $47 \%$ ( $p<0.0001)$. Similarly, in the report published by Baiocchi et al. [17] the absence of PLN involvement was associated with increased survival, and they also determined that PLN status was an important prognostic factor. Uno et al. [15] found that the 5-year OS rate for patients with negative PLN was $89 \%$. For patients with one positive PLN, they had a 5 -year OS rate of $83 \%$, and for patients with 2 or more positive pelvic lymph node metastases, the

Table 5. Multivariate analysis for significant prognostic factors

$\begin{array}{lccc}\text { Prognostic factor } & \text { OR } & 95 \% \mathrm{Cl} & p \text {-value } \\ \text { PLN involvement } & 0.74 & 0.58-0.95 & 0.018 \\ \text { PI } & 0.62 & 0.43-0.91 & 0.015 \\ \text { SMS } & 1.14 & 1.03-1.26 & 0.011\end{array}$

Cl-confidence interval; PLN - pelvic lymph node; PI - parametrial invasion; SMS - surgical margin status 
Table 6. Estimated 5-year and 10-year overall survival rates

$\begin{array}{lcccccc}\text { Subgroups } & \text { Variables } & \text { 5-year OS (\%) } & \text { Standard error (\%) } & \text { 10-year OS (\%) } & \text { Standard error (\%) } & p \text {-value } \\ \text { PLN } & \text { positive } & 49.0 & 4.7 & 41.1 & 5.0 & 0.001 \\ & \text { negative } & 67.1 & 2.0 & 52.0 & 2.7 & \\ \text { PI } & \text { positive } & 54.3 & 2.4 & 39.7 & 2.9 & 0.001 \\ & \text { negative } & 79.2 & 2.6 & 66.7 & 3.6 & \\ \text { SMS } & \text { positive } & 60.9 & 3.3 & 51.4 & 6.7 & 0.001 \\ & \text { close margin* } & 64.3 & 21.0 & 64.3 & 21.0 & \\ & \text { negative } & 85.4 & 3.3 & 64.5 & 6.5 & \end{array}$

*Close margin was defined as cancer present 1 to $3 \mathrm{~mm}$ from the surgical edge.

PLN - pelvic lymph node; PI - parametrial invasion; SMS - surgical margin status

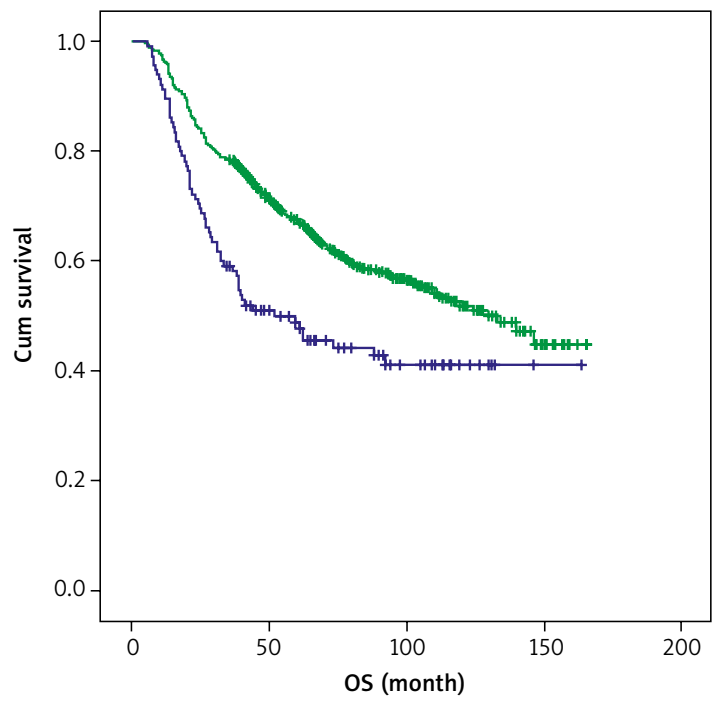

Pelvic lymph node involvement

$\neg$ positive $\quad+$ positive - censored

$\neg$ negative + negative - censored

Fig. 1. Overall survival (OS) curves for pelvic lymph node involvement

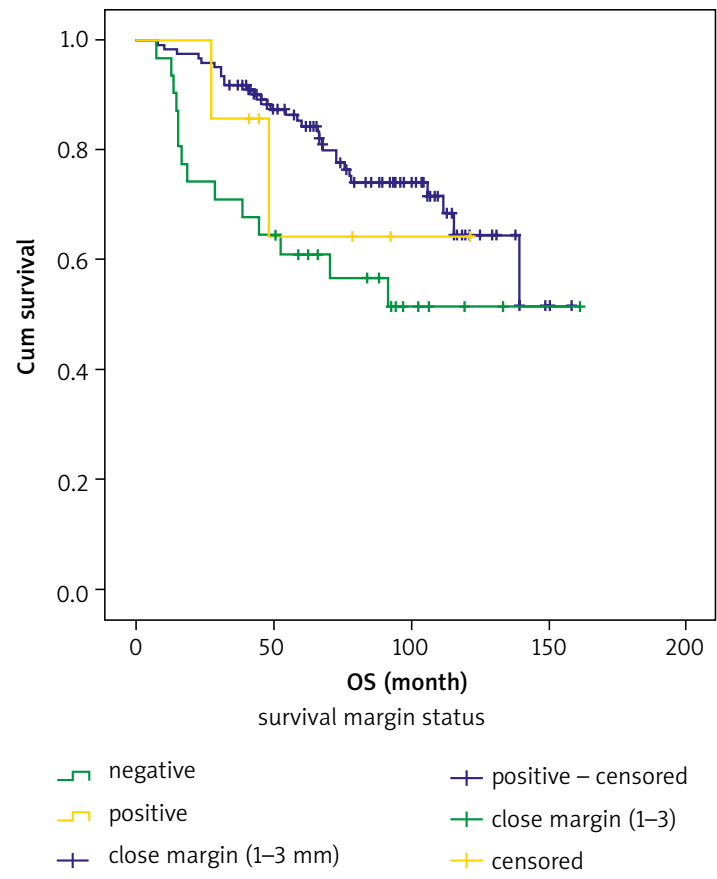

Fig. 3. Overall survival curves for surgical margin status

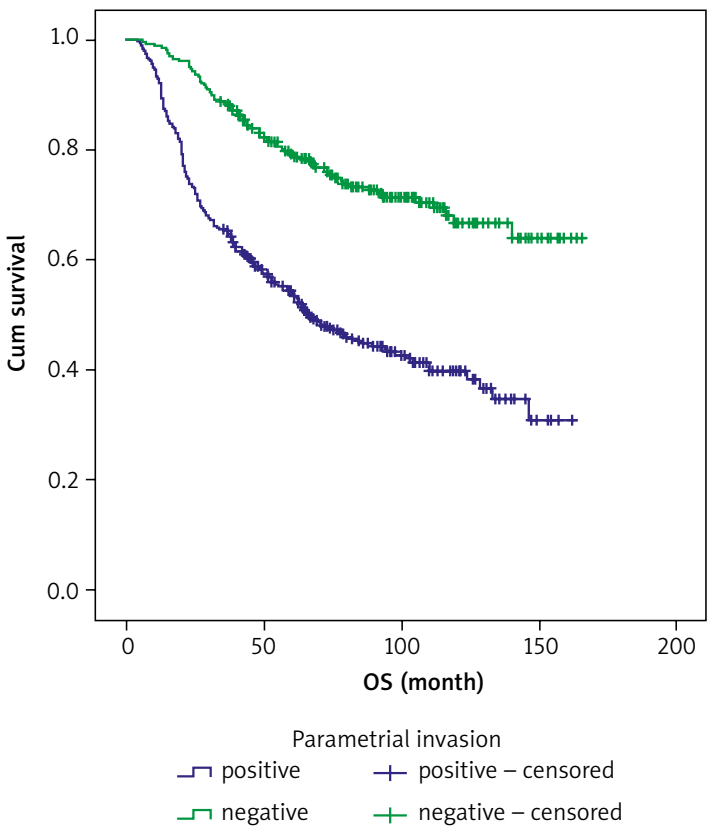

Fig. 2. Overall survival curves for parametrial invasion

5-year OS rate was 58\% ( $p=0.007)$ [17]. In a study of 106 patients who underwent pelvic exenteration by Maggioni et al. [23], 22 patients with cervical and vaginal cancer had lymph node involvement in the final pathology reports. Maggioni et al. [23] found that the 5-year survival rate for patients with negative PLN was dramatically better at $60 \%$, while patients with lymph node metastasis had a 5 -year survival rate of $30 \%(p=0.0446)$.

In contrast to the studies performed by Rutledge and McGuffee [25] and Marnitz et al. [24], we found that PLN metastasis is an important prognostic factor. In the study by Rutledge and McGuffee [25], it was found that PLN status was not associated with survival. Rutledge and McGuffee [25] concluded that some long-term survivals can be achieved if they are completely resected. Thirty-six percent of the patients who had positive pelvic nodes survived by the end of the 3-year follow-up period, as compared with the $26 \%$ who survived after 5 years. In addition to the study by Rutledge and McGuffee [25], Marnitz et al. [24] reported that lymph node metastasis did not correlate with survival in patients who underwent pelvic exenteration.

Our Cox proportional hazard model analysis revealed that PLN involvement was an independent prognostic fac- 
tor for cervical cancer survival $(p=0.018)$. The 5 -year and 10 -year overall survival rates for patients with negative PLN were $67.1 \%$ and $52.0 \%$, respectively. These survival rates were higher than for patients with positive PLN, as the 5 -year OS was $49.0 \%$ and the 10 -year OS was $41.1 \%$ $(p=0.001)$. In addition to lymph node positivity, Zreik et al. [6] determined that the presence of parametrial involvement significantly shortened the disease-free interval (DFI) $(p=0.039)$ and overall survival $(p=0.036)$ in patients with cancer-positive lymph nodes. The multivariate analysis performed by Zreik et al. [6] showed that a cancer-positive parametrium was a poor and independent prognostic factor for DFI when compared with patients with positive PLN only, irrespective of cancer positivity in the lymph nodes ( $p=0.043)$. Liu et al. [16] demonstrated that the 5 -year OS rate was $53 \%$ in patients with parametrial cancer involvement, while the rate was $89 \%$ in patients without parametrial involvement. Monk et al. [4] reported that patients with positive lymph nodes had a 5 -year survival rate of $78 \%$ when parametrial involvement was absent, but the 5 -year survival rate decreased to $39 \%$ when the cancer extended into the parametrium $(p<0.05)$.

In contrast to our study, Marnitz et al. [24] concluded that parametrial involvement has no statistically significant impact on long-term survival in patients who undergo pelvic exenteration. In our multivariate analysis, we determined that parametrial involvement was an independent prognostic predictor for OS, and the 5-year and 10 -year OS rates were $54.3 \%$ and $39.7 \%$ for positive PI vs. $79.2 \%$ and $66.7 \%$ for negative PI, respectively. Surgical margin status is the most consistently identified prognostic factor for cervical cancer [18, 22-24]. Marnitz et al. [24] reported that a clean surgical margin was significant for OS prognosis. The 2-year and 5-year OS rates for patients with cancer-free surgical margins were $55.2 \%$ and $44.8 \%$, respectively, but the 2 -year survival rate was only $10.2 \%$ for patients with cancer-positive margins ( $p=0.0057$ ).

In a study of 106 patients who underwent pelvic exenteration with vulvar, vaginal, cervical, uterine, and ovarian cancer by Maggioni et al. [23], 27 patients had positive surgical margins in the final pathological examination when only patients with cervical and vaginal cancer were evaluated. Their data showed statistically higher survival for patients with cancer-free surgical margins than for patients with positive surgical margins for patients with cervical or vaginal cancer who were treated with pelvic exenteration. Survival rates for patients with cancer-free surgical margins and cancer-positive margins were $60 \%$ and $25 \%$ at 5 years, respectively $(p<0.05)$ [23]. In addition, Fotopoulou et al. [22] found that a negative surgical margin was significant in improving OS and progression-free survival. Similarly to previous reports $[18,23,24]$, we found that positive surgical margins were a predictor of an unfavourable outcome in patients with cervical cancer in our study. We determined that the 5 -year OS rates were $85.4 \%$ for patients with a negative surgical margin, $60.9 \%$ for patients with a positive surgical margin, and $64.3 \%$ for patients with a close margin of $1-3 \mathrm{~mm}(p<0.05)$.

There were several limitations in our study. Firstly, this was a retrospective study, and secondly, risk factors such as LVSI, DSI, SMS, greatest tumour diameter, and tumour grade were unknown for most patients. Lastly, we evaluated all stages of cervical cancer in our study, ranging from FIGO stage IA to IVB, and did not evaluate survival for each FIGO stage separately.

In conclusion, evaluating pelvic lymph node metastases, parametrium involvement and surgical margins is important in predicting long-term survival outcomes for patients with cervical cancer. These prognostic factors may help physicians determine which patients are more likely to have better treatment outcomes and may guide the decision as to which patients receive more aggressive and further adjuvant therapies. It is necessary to perform future prospective, randomized studies with a larger study sample to better determine prognostic factors that may aid in determining optimal treatments for cervical cancer patients.

We are grateful to Dicle University DUBAP for assistance in editing the English version of this manuscript.

\section{The authors declare no conflict of interest.}

\section{References}

1. Monk BJ, Tewari KS, Koh WJ. Multimodality therapy for locally advanced cervical carcinoma: state of the art and future directions. J Clin Oncol 2007; 25: 2952-65.

2. Bray F, Carstensen B, Møller H, Zappa M, Zakelj MP, Lawrence G, Hakama M, Weiderpass E. Incidence trends of adenocarcinoma of the cervix in 13 European countries. Cancer Epidemiol Biomarkers Prev 2005; 14: 2191-9.

3. Wagner AE, Pappas L, Ghia AJ, Gaffney DK. Impact of tumor size on survival in cancer of the cervix and validation of stage IIA1 and IIA2 subdivisions. Gynecol Oncol 2013; 129: 517-21.

4. Monk BJ, Cha DS, Walker JL, Burger RA, Ramsinghani NS, Manetta A, DiSaia PJ, Berman ML. Extent of disease as an indication for pelvic radiation following radical hysterectomy and bilateral pelvic lymph node dissection in the treatment of stage IB and IIA cervical carcinoma. Gynecol Oncol 1994; 54: 4-9.

5. Aoki Y, Sasaki M, Watanabe M, Sato T, Tsuneki I, Aida H, Tanaka K. High-risk group in node-positive patients with stage IB, IIA, and IIB cervical carcinoma after radical hysterectomy and postoperative pelvic irradiation. Gynecol Oncol 2000; 77: 305-9.

6. Zreik TG, Chambers JT, Chambers SK. Parametrial involvement, regardless of nodal status: a poor prognostic factor for cervical cancer. Obstet Gynecol 1996; 87 (5 Pt 1): 741-6.

7. Sevin BU, Lu Y, Bloch DA, Nadji M, Koechli OR, Averette HE. Surgically defined prognostic parameters in patients with early cervical carcinoma. A multivariate survival tree analysis. Cancer 1996; 78: 1438-46.

8. Samlal RA, van der Velden J, Ten Kate FJ, Schilthuis MS, Hart AA, Lammes FB. Surgical pathologic factors that predict recurrence in stage IB and IIA cervical carcinoma patients with negative pelvic lymph nodes. Cancer 1997; 80: 1234-40.

9. Sedlis A, Bundy BN, Rotman MZ, Lentz SS, Muderspach LI, Zaino RJ. $A$ randomized trial of pelvic radiation therapy versus no further therapy in selected patients with stage IB carcinoma of the cervix after radical hysterectomy and pelvic lymphadenectomy: A Gynecologic Oncology Group Study. Gynecol Oncol 1999; 73: 177-83.

10. Burke TW, Hoskins WJ, Heller PB, Bibro MC, Weiser EB, Park RC. Prognostic factors associated with radical hysterectomy failure. Gynecol Oncol 1987; 26: 153-9.

11. Sevin BU, Lu Y, Bloch DA, Nadji M, Koechli OR, Averette HE. Surgically defined prognostic parameters in patients with early cervical 
carcinoma. A multivariate survival tree analysis. Cancer 1996; 78: 1438-46.

12. Lai CH, Chang HC, Chang TC, Hsueh S, Tang SG. Prognostic factors and impacts of adjuvant therapy in early-stage cervical carcinoma with pelvic node metastases. Gynecol Oncol 1993; 51: 390-6.

13. Soisson AP, Soper JT, Clarke-Pearson DL, Berchuck A, Montana G, Creasman WT. Adjuvant radiotherapy following radical hysterectomy for patients with stage IB and IIA cervical cancer. Gynecol Oncol 1990; 37: 390-5.

14. Hopkins MP, Morley GW. Stage IB squamous cell cancer of the cervix: clinicopathologic features related to survival. Am J Obstet Gynecol 1991; 164 (6 Pt 1): 1520-7; discussion 1527-9.

15. Uno T, Ito H, Itami J, et al. Postoperative radiation therapy for stage IB-IIB carcinoma of the cervix with poor prognostic factors. Anticancer Res 2000; 20 (3B): 2235-9.

16. Liu MT, Hsu JC, Liu WS, et al. Prognostic factors affecting the outcome of early cervical cancer treated with radical hysterectomy and post-operative adjuvant therapy. Eur J Cancer Care (Engl) 2008; 17: 174-81.

17. Baiocchi G, Guimaraes GC, Rosa Oliveira RA, et al. Prognostic factors in pelvic exenteration for gynecological malignancies. Eur J Surg Oncol 2012; 38: 948-54.

18. Fleisch MC, Pantke P, Beckmann MW, Schnuerch HG, Ackermann R, Grimm MO, Bender HG, Dall P. Predictors for long-term survival after interdisciplinary salvage surgery for advanced or recurrent gynecologic cancers. J Surg Oncol 2007; 95: 476-84.

19. Inoue T, Morita K. The prognostic significance of number of positive nodes in cervical carcinoma stages IB, IIA, and IIB. Cancer 1990; 65: 1923-7.

20. Kamura T, Tsukamoto N, Tsuruchi N, Saito T, Matsuyama T, Akazawa K, Nakano H. Multivariate analysis of the histopathologic prognostic factors of cervical cancer in patients undergoing radical hysterectomy. Cancer 1992; 69: 181-6.

21. Aoki Y, Sasaki M, Watanabe M, Sato T, Tsuneki I, Aida H, Tanaka K. High-risk group in node-positive patients with stage IB, IIA, and IIB cervical carcinoma after radical hysterectomy and postoperative pelvic irradiation. Gynecol Oncol 2000; 77: 305-9.

22. Fotopoulou C, Neumann U, Kraetschell R, Schefold JC, Weidemann H, Lichtenegger W, Sehouli J. Long-term clinical outcome of pelvic exenteration in patients with advanced gynecological malignancies. J Surg Oncol 2010; 101: 507-12.

23. Maggioni A, Roviglione G, Landoni F, et al. Pelvic exenteration: Ten-year experience at the European Institute of Oncology in $\mathrm{Mi}$ lan. Gynecol Oncol 2009; 114: 64-8.

24. Marnitz S, Köhler C, Müller M, Behrens K, Hasenbein K, Schneider A. Indications for primary and secondary exenterations in patients with cervical cancer. Gynecol Oncol 2006; 103: 1023-30.

25. Rutledge FN, McGuffee VB. Pelvic exenteration: Prognostic significance of regional lymph node metastasis. Gynecol Oncol 1987; 26: $374-80$

\section{Address for correspondence}

\section{Fatma Teke}

Dicle University

Diyarbakır, Turkey

e-mail: doktorfatmateke@gmail.com

Submitted: 23.09 .2014

Accepted: $\quad 6.10 .2014$ 